\title{
KNOWLEDGE AND METHODS IN IS RESEARCH: FROM BEGINNINGS TO THE FUTURE
}

\author{
Heınz K. Kleın \\ State University of New York Binghamton \\ U.S.A.
}

\begin{abstract}
The purpose of this paper is to identify some of the key challenges that the Information Systems research community needs to address in order to improve interpretive and critical research approaches in the next decade. In order to achieve this goal, a high level review of the principal trends in IS research methodology since the late 1960s set the stage for an analysis of challenges to be met in the next decade. The past trends in IS research methods are analyzed from the perspective of two questions: what is the implied concept of knowledge and what are the methods of inquiry preferred by various research methods schools? Even though the analysis attempted here should be viewed as tentative and preliminary, it leads to several provocative conclusions. The most significant of these concern the interrelationships between critical and interpretive research.
\end{abstract}

Keywords: Evolution of research methods in information systems, current research methods and their limitations, inquiry methods, ethical standards, rules in information systems development, ethnography, confessional genre, critical theory research, cross-paradigm approaches.

\section{Introduction}

When I first read the call for papers of this conference, I was struck by a paradox, which ultimately contributed to my acceptance of the invitation for a keynote speech to this 
conference. I am very grateful to the organizers for offering me this forum for articulating some of my recent reflections on the current state of IS (Information Systems) research. While my ideas are still very much in the making, their preliminary status will not keep me from offering some provocative propositions.

The call for papers of this conference refers to the common observation that the many IT innovations cause a wide range of social transformations. There is a note of alarm in bemoaning that "These radical social transformations of organizations are taking place át such a speed that they are overwhelming for academic researchers." What is needed are general concepts to classify the mind-taxing variations of organizational transformations into a parsimonious typology. Something like the table of elements would be ideal, because it also has predictive power. We also need abstract theories that allow reducing the complexity of organizational reality transformations into a few comprehensible patterns just as Newtonian axioms bring order into the diverse phenomena of mechanics.

Alas, the call for papers takes the reader in an entirely different direction, when it states that "we are interested in field studies that discuss social and organizational issues around the implementation and use of these new technologies in organizational processes." I find this paradoxical, because field studies are predominantly ideographic, i.e., they tend to report the differentiating details of cases and make only weak attempts at classification and generalization. If there are an "overwhelming" number of different social transformations, they will then be reflected in an equally overwhelming number of different field studies pursued with a bewildering variety of research method variations.

The hypothesis that I wish to explore with you in this paper is that the paradoxical turn, which I perceived in the call for papers of this conference, is by no means an accident. It has become typical for a great many conferences in industry and academia. Why is it that many scholarly institutions in IS currently appear to be shying away from the noble pursuit of theory? Is there widespread disenchantment, maybe even discontent, with theory and, if so, why? My purpose is to deal with these questions in a way that could support a communal reflection on the path that IS research has taken during the last three decades. Only by looking back at how we got here can we become more critically aware of the choices that we are about to make as we move into the fourth millennium. (I start my count with the first 1000 years before Christ, which brings the Presocratics and classical Greek philosophers into the elite of human knowledge creators.)

\section{Approach}

In reflecting upon three decades of IS research and the role that my research associates played in the evolution of the fundamental tenets underlying IS research, I am struck by how the meaning of the simple word knowledge has changed in a relatively short time for our discipline. Clearly one cannot consider the question "what do we mean by knowledge?" without also bringing the methods of knowledge creation into the bargain. Knowledge and the preferred methods of inquiry used to create knowledge form an inseparable unit. If one changes, so must the other. Methods of knowledge creation cover a wide variety of human behaviors, from the way families acquire knowledge for 
conducting their lives, from jury and court decisions to organizational knowledge creation and academic communities. For obvious reasons, I will by and large limit myself to discussing the kind of preferred methods of knowledge creation in the IS community that we typically call research methods. For a convenient collection of such research methods I refer to Mumford et al. (1985) and Nissen, Klein and Hirschheim (1991).

My approach will be to trace the interdependence of knowledge over the life of our discipline and relate the main stages of this evolution to broader philosophical ideas. I will then ask, what is the most recent turn in our search for knowledge both with regard to the characteristics that define what counts as knowledge and with regard to the evermoving front of research methods? In particular, what do the most recent proposals for refining our research methods imply for the concept of knowledge? To clarify the basic plot of my investigation a little further, I would like to give an example of the interdependence between knowledge and research methods by referring to five historical figures. We all heard about some of the kingpins in the Western history of knowledge creation such as Plato, Euclid, Kant, Newton and Einstein. (Note that these figures come from two of the three millennia of knowledge creation in Western philosophy and science, one millennium B.C. and one after the year 1000. I did not dare to face the tricky question: who are the principal knowledge creators during the first 1000 years A.D.?) While all of these five historical figures contributed to our stock of knowledge and all still exert strong influence on modern thought, the methods they followed are vastly different and so is the concept of what they meant by knowledge. For example, Plato and Kant explicitly included ethics (the moral imperative) into the realm of knowledge, while the others did not. Moreover, the example makes it patently clear that research methods may change radically. The methods of the first four figures are no longer acceptable to their present-day successors.

The question I wish to pursue in some detail is who have been the kingpins of knowledge during the last three decades of IS research and what have been their preferred research methods? Ancillary questions are why do we, their successors, no longer follow these preferred methods (what are their shortcomings) and which methods have been substituted for them? And finally, where does this all take us as the third millennium of Western knowledge creation comes to an end?

How should we break down 30 years of IS research into a few major streams that can be discussed in the short space available for this paper? As far as the concept of knowledge is concerned, I intend to critically examine representative crown witnesses from the prevailing academic literature in IS with the dichotomous distinction between facts and norms. I shall inquire from the prevailing lines of research, whether they were primarily concerned with descriptive knowledge or whether their definition of knowledge was so broad as to include normative knowledge. The typical forms of normative knowledge are norms, rules and values. Rules are important in the practice of any profession-e.g., management, engineering, medicine, law-but they play a particularly prominent role in ISD (information systems development). To further characterize the kinds of rules that are typical for the normative side of knowledge, I shall apply Kant's distinction between rules skill, rules of prudence and categorical rules (to which I shall refer as ethical values). Rules of skill are concerned with the physical propensity and dexterity to carry out certain operations to achieve specified ends. Rules of prudence are concerned with judgments to achieve ends that informed and reasonable 
people would not question as being worthwhile, such as designing systems which are acceptable to their intended users. Categorical rules are concerned with choices where the ends themselves are in question, such as a choice between developing systems which are preferable to one set of stakeholders (e.g., workers on the shop floor) or another (e.g., a company's shareholders). Categorical rules are particularly important when our discipline has to deal with social value conflicts in practice and hence I shall refer to them as ultimate values or ethical standards. Klein and Hirschheim (1998) provide a fuller treatment of these ideas.

In order to analyze changes in preferred research methods over time, I shall draw on the seminal book by W. Churchman, The Design of Inquiring Systems: Basic Concepts of Systems and Organization, 1971. In this book, Churchman proposed that the principal methods of knowledge creation (inquiring method as he called them), can be broken down into five basic epistemological types: Cartesian, Lockean, Leibnizian, Kantian and Hegelian types of inquiry. Modern research methods are descendants of the last three combining and varying their characteristics. A key characteristic of modern research methods is that they all have abandoned the idea that knowledge begins with simple and clear entities, that we can start with basics that are obviously true and build more complex theory on secure foundations that are beyond doubt. This eliminates Cartesian and Lockean types of inquiry from serious consideration. Yet, early IS research, to some extent, did subscribe to Cartesian and Lockean inquiry ideals.

Of course, the five epistemological types of inquiry do not neatly follow each other in time, but are recognizable as literature pools and quoting cartels overlapping in time. However, a convenient landmark to break the last 30 years of IS research into two periods is the explicit recognition of multiple paradigms in widely read, so called premier journals. This occurred around 1989 because of two key events. One was the appearance of three "paradigmatic" articles in the Communications of the ACM in short succession: Banville and Landry, Hirschheim and Klein and, in opposition to these two, Denning et al. Of course, the recognition of multiple paradigms in the research establishment could not have occurred without some precursors such as Mumford et al. 1985, Chua 1986 and Galliers and Land 1987. These paved the way for a broader based attitude change in several research communities. There is a certain irony to temporal coincidence of the 1989 publications. Neither of the three sets of authors were aware of each other's projects even though the first two papers reached almost identical conclusions and there would have been plenty of time for contacts as the review process took several years. A second key event was the conversion of MIS Quarterly from a single paradigm journal to one that would restructure its review process so that contributions from alternative paradigms would receive a fair shake without jeopardizing high standards. Whereas there have always been "alternative community journals" (e.g., Information, Technology and People, edited by E. Wynn, has offered strong support for interpretivist research for quite some time), the journal culture began to shift toward multiple paradigm publication venues. Younger researchers often don't recognize that this amounted to radical, institutional change.

What follows is a review of my current state of thought on these issues. It is a first draft that cannot do justice to all the questions raised in the introduction.

The remainder of this paper previews some of the key ideas in draft form, which I shall develop more fully for the conference presentation. In the interest of brevity, I need to be highly selective, simplify many aspects and fall short of answering all the issues 
raised in the introduction. While I will draw on my knowledge of the historical evolution of IS research, I don't intend to write an authoritative history of IS research methodology, but merely highlight major epistemological shifts in IS research. An epistemological shift occurs if there are major changes in the concept of what counts as knowledge or the preferred research methods.

\section{Archtypcial Patterns in the Pre-1989 Era of IS Research}

The purpose of this section is to illustrate three observations about the general characteristics of IS research during the era from the mid-1960s to the end of the 1080s. First, while the MIS publications of the very early period dating back to mid-1960s were methodologically less rigorous, they exhibited much concern for both descriptive and normative knowledge with a variety of inquiry methods. A good collection of them can be found in Sanders (1970), but one of the best-known examples is probably Ackoff's 1967 classic paper on MIS-misinformation systems. The papers of this genre apply Lockean types of inquiry in that they rely on clear and simple observations and use common sense logic to establish plausible conclusions of a normative type. They often have the ring of stories; therefore, this stage in IS research has sometime been called the era of "great wise men." One of the surprising turns of recent research is the rehabilitation of the story concept as a legitimate research genre - but let me not get ahead of myself.

My second observation moves us further ahead into the 1970s when the so-called experimental school of IS research (beginning with the Minnesota Experiments, Dickson et al. 1977) substantially increased the requirements for methodological rigor, but at the same time the practical relevance of this type of MIS publications decreased. One of the most visible counter-reactions to this trend was the reorganization of Communications of the ACM a few years ago. Nevertheless, when judged by sheer numbers of paper titles, several studies concluded that $90 \%$ or more the body of knowledge published in journals falls into this category and it still is the dominant schools that attracts the most disciples. The principal mode of inquiry of this line of research is Kantian with almost exclusive emphasis on descriptive types of theoretical knowledge. It is Kantian, because this kind of research proceeded from formulating theoretical hypotheses to derivation of conclusions or prediction which could then be tested empirically using sophisticated statistical inference methods. Hence this kind of research, which is still very active, emphasizes an internal model with a complex logic that is used to make sense of outside data. It is commonly referred to as the positivist model of scientific research.

Parallel to the experimental methods of inquiry, several other lines of research flourished during the same era using research methods of a very different kind. Most of these were applied in the area known as ISD (information systems development). ISD research at that time created the knowledge core that defined the identity of our discipline as is apparent from the article by Ives, Hamilton and Davis (1980). (Do we still have such an identity defining knowledge core?) Very significant influences to improve ISD came from action research (e.g., Checkland 1972), which is still going strong. Action research equally emphasizes descriptive and normative knowledge at the level of rules of skill and rules of prudence in our field, but generally it stops short of 
contributing critical evaluation of ethical standards. In the early years, a substantial amount of research on ISD centered on the participation debate in ISD (Mulder 1971; Mumford 1983, 1984; Greenbaum and Kyng 1991). In this context, important intellectual and political insights were contributed to our understanding of the broader social issues surrounding ISD by the so-called trade union or collective resource school within the Scandinavian School. (Kyng and Mathiassen [1982], Kyng [1991], Bansler [1989], Bjerknes and Bratteteig [1995], and Mathiassen [1999] present good literature analyses of major contributions from the Scandinavian School to IS research.)

Another major impetus for advancing the state of the art in ISD came from engineering research into the development of the first generation computer-based tools of ISD (cf. Couger, Coulter and Knapp 1982 for a review of several projects in this area). All of these streams research, which often were carried out separately without the benefit of mutual communication and debate, contributed to a larger body of knowledge which became known as alternative methods and tools of ISD. The prototyping and decision support systems research (e.g., Keen and Scott-Morton 1978; Budde et al. 1984 ) is also part and parcel of the extensive research on ISD before 1990.

The core knowledge created by all these research streams incorporates both descriptive accounts of how ISD is actually carried out in practice, empirically tested hypothesis among environment, process and ISD outcome variables (Ives, Hamilton and Davis 1980) and normative knowledge including ethical standards. Figure 1 gives a summary of some of the principal value standards that emerged from the debate on the ultimate goals of ISD. The most widely espoused value standard is, of course, the private enterprise ideal. It insists that the common good is best served if IS improves the competitiveness and profitability of private enterprise and is subject to some minimal legal constraints on privacy, job security, etc. All else is secondary. The research methods of the research on ISD defy a simple description. It spans several paradigms (cf. Hirschheim, Klein and Lyytinen 1995 for more extensive discussion) combining elements of Kantian, Leibnizian and Hegelian, i.e., dialectical, methods of inquiry.

The best examples for Leibnizian inquiry are found in the literature from the computer simulation movement. It built very complex models and investigated the consequences of the complex assumptions that were built into the model. Hence it started with complex assumptions the truth of which was unclear ("contingent truths"). By running the model and looking at its output, it was hoped that the model could eventually be improved. This idea is basically Leibnizian. As we all know, the enthusiasm for computer simulation as a research method died in the early 1980 s.

Third, in the 1980s, the narrow epistemological assumptions of the positivist line of IS research became ever more apparent to researchers who were aware of the philosophical critiques of positivism (cf. the literature analysis in Klein and Lyytinen 1985). Eventually this led to a valiant attack on positivism from several directions. The paradigm controversy in the IS literature made many more researchers aware of the importance of dialectical research methods and established the notion of methodological pluralism, which characterized the debate in the 1990s. 
(A) Socio-technical Ideal. The principle objective is to optimize the interrelationships between the social and human aspects of the organization and the technology used to achieve organizational goals. Both the quality of working life (satisfaction of human needs at work) and profitability or system efficiency are to be improved through a high degree of fit between job characteristics (as defined by work design) and a limited set of human needs (as defined by social and psychosomatic profiles).'

(B) Decision Support Systems Ideal. The final criterion is "to help improve the effectiveness and productivity of managers and professionals." A necessary condition for achieving this is to gain user acceptance and actual systems use. In some parts of the literature, this is seen as a worthwhile goal in itself. In any case, the emphasis is on tailoring the system design to the user's needs and preferences. Sophisticated techniques for analysis of personality traits or other psychometric variables such as cognitive style, locus of control, motivational type, attitudes, etc., are proposed as design tools. Thorough "understanding" of the user's problems and a strategy of mutual trust building through highly participative systems development in a series of small, adaptive steps with rapid feedback through demonstrations are seen as the "right" approach.

(C) Dialectical Inquiry Ideal. Above all, information systems must be designed such that they produce maximal motivation to generate "objective" knowledge through the synthesis of the most opposing points of view, each supported by the best available evidence. Truth and objectivity are of prime importance and can only be found through an adversary system in which the competing points of view are confronted such as in a court of law. Peace, willingness to compromise, or consensus creates dangerous illusions, which threaten the objectivity of knowledge and justice (cf. Churchman 1970, 1981; Mason 1969; Cosier et al. 1978).

(D) Participatory Design Ideal. Emphasizes that the process by which systems are developed may be more important than the features of the final product, because "people should be able to determine their own destinies." Hence the ultimate moral value to be achieved through participation is human freedom, which then leads to such other goods such as motivation to learn, genuine human relationships based on equality and commitment to what one has freely chosen to accomplish (Mumford 1983; Land and Hirschheim 1983).

${ }^{\text {I }}$ Proponents of the socio-technical ideal usually stress that it will improve profitability through higher worker satisfaction (and ignore a possible conflict between the two). The dialectical inquiry (DI) ideal has been tried in the context of improving private enterprise planning (Mason 1969) and the decision support system (DSS) approach stresses "managerial effectiveness" over technical cost savings. DI and DSS could be treated as end goals, but are primarily seen as instrumental for achieving other final ends. The socio-technical and private enterprise ideals are examined in detail in Klein (1981).

Figure 1. Ultimate Goals or Ethical Standards Identified in the Literature on Methods and Tools of ISD (Klein 1981) 


\section{Beyond 1989: Dialectics and Methodological Pluralism}

Even though Mason introduced the basic ideas of dialectical inquiry (originally due to Hegel) into the management literature as early as 1969 in Management Science, it took about two decades for dialectical concepts to exert major influence on IS research. Dialectical inquiry insists that the growth of knowledge benefits most from social processes that are propelled by conflict and passion. A dialectical inquiring system consists of at least two actors with differing worldviews or perspectives by which they interpret the world in conflicting ways. Each actor has access to a separate data pool (her accepted "facts") that only partly overlap with the data of the other actor or actors. Each actor possesses her own logic and modes of reasoning, again not completely congruent. Knowledge emerges from debating the contradictions among the beliefs, inference methods and data of each actor. By eliminating some of the contradictions in reformulating the worldviews of some of the actors, a higher level of knowledge is reached. This new worldview incorporates the best of its antecedents and is called a "synthesis." The synthesis is the starting point for a new cycle of debate with an emerging opposing viewpoint and the process repeats.

The Burrel and Morgan (1979) classification of research paradigms in sociology provided a convenient description of prevailing worldviews among researchers in the 1980s. Hence, when the aforementioned papers by Banville and Landry and by Hirschheim and Klein appeared, they offered a convenient intellectual rationalization for what many IS researchers intuitively had come to accept: that there are rather different approaches to ISD and other issues in IS research. By contrast, the third paper (Denning et al.), formulating the opposing positivist viewpoint as a research paradigm for Computer Science, was almost completely ignored in IS. This further widened the intellectual gap with Computer Science. Instead of debate about paradigms, a quiet shift to pluralism occurred. The idea that ruled the first 20 years of IS research, namely that the one and only orthodox method science fits all, was abandoned within the relatively short space of a few years-much to the surprise of this author.

The result of this was the emergence of several alternative research streams as viable $\mathrm{Ph} . \mathrm{D}$. dissertation projects and "tenurable" research programs. It has now become accepted that there are three research paradigms in IS research, namely the positivist, the interpretivist and the critical. The field is now also willing to consider such radical alternatives as post-modernism or deconstructionism, at least tentatively. Nevertheless, when counting sheer numbers of disciples in each paradigm, some version of positivism is still the most frequent type of research. However, publications that are guided by interpretivist modes of inquiry are on the rise. There is a dearth of critical inquiries. Most critical research published is concerned with fundamentals, such as Klein and Lyytinen (1991), Hirschheim and Klein (1994) or Ngwenyama and Lee (1997). It is my contention that an analysis of the reasons for this grants little comfort and provides future researchers with major challenges. Nevertheless, many researchers, including positivists nowadays will agree that if interpretivist and critical research publications are weighed in as a new body of knowledge that has emerged in the 1990s, as a whole it successfully challenges the knowledge and research methods monopoly of positivism. Even such a bastion of positivism in our field as the Decision Sciences Institute sponsored a special round table panel session in March 1999 (North Eastern Decision Sciences Institute, New Providence) with the provocative title: "Organizational 
Research in the $21^{\text {st }}$ Century: Have We Made a Qualitative Shift?" Many of us can no longer avoid the impression that we are currently living through a "scientific revolution" in our field in the sense of Kuhn (1970). But where do we go from here?

\section{Stories Lost, Stories Found: Challenges for the Next Decade}

Judging by the recent surge of interpretivist dissertations, conferences and journal publications, the ethnographic and intensive field study species of interpretivists are enjoying the equivalent of a communal honeymoon. However, there are several points that I would like to make in the conclusion, which give us little reason for comfort. First, the field started with story telling that was then debunked as "unscientific." It now appears has if IS research has come full circle by returning to new forms of story telling (the politically correct term is, of course, "narratives'). Granted that the new story telling movement can point to much better and more explicit philosophical grounding than "the great wise men" had for their stories, I still wonder to what extent all the recent converts truly understand the intellectual foundations of their newly found faith. If one asks, just what are the methods by which the new breed of storytellers distinguishes themselves from their ancestors, one realizes that the debate on proper methods for interpretivist research has barely begun (e.g., Klein and Myers 1999; Schultze 1999). If and when we get such a debate off the ground with broad participation, it offers the chance of rapid, dialectical growth of knowledge. However, along with this chance for a debate also looms the danger of sectarianism - the split in subcommunties, which prefer to ignore each other rather than to engage each other in critical dialogue.

My second conclusion concerns the reasons why there appears to be a surge of interpretivist research as is so evident from this and the preceding Philadelphia conference (see Lee, Liebenau and DeGross 1997). While there is room for many different types of answers, I offer the following conjecture. To a major part, these reasons have to do with the failure of positivist research to offer a few broad theories that offer general orientation and bring some measure of order to the perpetual confusion in our field. Alas, interpretivists have little reason to be gleeful about this. They are even weaker in theory formulation than the positivists. Should it turn out that they are equally unable to deliver the goods, they may fall into disrepute much quicker than the attraction of positivism is waning. It may turn out that neither emperor has any clothes.

Third, what about critical theory research? While it has strengths exactly in the areas in which interpretivism is weak, i.e., theory formulation and normative knowledge, its empirical grounding is extremely weak. In fact, one can only be astonished how an eminent philosopher like Habermas deals with this issue. Moreover, if one asks which methods can be taught to aspiring critical researchers, one draws almost a blank card. There appears to be no research methods literature on critical research. This is evident from Forester (1992). It will take a whole generation of researchers to create such a literature. Some beginnings can be found in Klein and Truex (1996) and Klein and Huynh (1999, in this proceedings), but the amount of work will need to increase dramatically from many different quarters if further progress is to be made; yet the successful outcome is uncertain no matter how many join this effort. 
Fourth, what about a possible union of critical research and interpretivism? In this area, I see great research opportunities, but let me first offer a few words of caution. The historical and conceptual connections between various forms of critical theory interpretivism are complex and therefore not well understood, maybe even by professional philosophers. I am therefore very skeptical if current attempts to integrate the two are founded on a clear understanding of their intrinsic connections. Why then do researchers interested in critical theory reach out to linguistic theory on the one hand (as is evident from my own publications) and to interpretivist field studies on the other (cf. Ngwenyama and Lee 1997)? It seems to me that it is merely the lack of a recognized stock of critical methods that provides the primary motivation for this. If so, current attempts to integrate these different conceptual bases are merely liaisons of convenience, because they are not based on an explicit reconstruction of the conceptual foundations that could give the newly found relationships staying power. Without proper theoretical foundations, it is merely of matter of convenience, if not desperation, to grab whatever avenue offers itself for data collection to experientially ground critical or other interpretivist ideas. Any port in a storm! It is convenient, because interpretivist methods of data collection and analysis provide a relatively safe haven, appeasing the researchers' understandable human need for some predictability and order in their work. However, unless the union can be based on a reasoned understanding that interpretivist and critical assumptions are at least partially compatible, the potential intellectual incongruence between the interpretivist approaches to data collection and the critical theory base could become the Trojan horse, which brings down the whole integration project.

Hence my fifth point is to call for serious work to construct the necessary theoretical and methodological bridges between critical theory and philosophy of language and interpretivism. This is an immense challenge for the IS research community. Clearly, critical theory is much more theory oriented than interpretivism, because it brings with it a strong legacy of Kantian a priori, at least in the version of Habermas' Critical Social Theory. (I offer this claim without substantiating it here.) Moreover, with its emphasis on a communicative orientation (or interest in human understanding), it explicitly relates to hermeneutics, which is also the heart of interpretivism. Therefore, I consider the full development of all the potential relationships between interpretivism and critical theory as one of the most fruitful avenues for future research. This union might very well be poised for a honeymoon, because of conceptual interrelationships in the underlying intellectual foundations of both critical social theory and interpretivism. For example, both relate to the philosophy of language (albeit in different ways, notice the use of speech act theory by Habermas), hermeneutics (e.g., Gadamer) and lifeworld philosophy.

However, none of the above addresses the shortcomings of interpretivism to contribute to the growth of normative knowledge. Its reluctance to address norm and value issues appears to make interpretivism incompatible with critical theory. I hope that future conceptual developments will somehow be able to overcome this limiting characteristic of interpretivism. For if not, I am sure of the following. IS theory will remain chronically incomplete if we as researchers simply ignore the immense importance of normative knowledge for practice and the general betterment of the conditions of human existence.

In summary, the first challenge for the next 10 years is to inject more methodological controls into interpretivism so that its result can gain the trust of researchers and practitioners alike while not losing its flexibility and sensitivity to situational 
differences. The second challenge for interpretivist research is to engage in more theorizing to provide generalizations, which promise to yield some order and predictability for our field. The third challenge is to find variations of the interpretivist approach, which allow entering a strong theoretical union with critical and other social theories. The hope is that interpretivist research can help with the experiential grounding of theoretical constructions and social theories of various couleurs could provide the theoretical bases to inspire more generalization and abstraction in interpretivist studies. Hopefully this enterprise will not get stuck in "middle range hypotheses" like positivism. In order to yield broad theoretical orientations, interpretivism must not follow positivism into the swamp of endless trivial hypothesis proliferation. The last and maybe biggest challenge for the future of IS research is to come to grips with the need for normative knowledge in our field that goes beyond rules of skill.

I know that some readers will react to these ideas with "here we go with yet another meta-narrative." My reply is that I do not seek the great, infallible truth, but merely some fallible theories in the sense of Popper's "Conjectures and Refutations" (1963), but of sufficiently broad scope. Interpretivists of all flavors should heed the often forgotten dictum that data without theory is blind and theory without data is empty. At the moment, interpretivists are more at risk to cause blindness than emptiness and the reverse is true for critical theorists.

\section{References}

Ackoff, R. “Management Misinformation Systems,” Management Science, December 1967, pp. 147-156.

Banville, C., and Landry, M. "Can the Field of MIS be Disciplined?" Communications of the $\operatorname{ACM}(32: 1), 1989$, pp. 48-60.

Bansler, J. "Systems Development Research in Scandinavia: Three Theoretical Schools." Scandinavian Journal of Information Systems (1), 1989, pp. 3-20.

Bjerknes, G., and T. Bratteteig, T. "User Participation and Democracy: A Discussion of Scandinavian Research on System Development," Scandinavian Journal of Information Systems (7:1), 1, April 1995, pp. 73-98

Budde, R.; Kuhlenkamp, K.; Mathiassen, L.; Zullighoven, H. (eds.). Approaches to Prototyping. Berlin: Springer-Verlag, 1984.

Burrell, G., and Morgan, G. Sociological Paradigms and Organizational Analysis. London: Heinemann, 1979.

Chua, W. F. "Radical Developments in Accounting Thought," The Accounting Review (61), 1986, pp. 601-632.

Churchman, C. W. Challenge to Reason. New York: Delta Books, 1970.

Churchman, C. W. The Design of Inquiring Systems: Basic Concepts of Systems and Organization. New York: Basic Books, 1971.

Churchman, C. W. The Design of Inquiry Systems. New York: Basic Books, 1981.

Cosier, R. A; Ruble, T. L.; Aplin J. C. "An Evaluation of the Effectiveness of Dialectic Enquiry Systems," Management Science (24:14), October 1978, pp. 1483-1490.

Couger, J. D.; Coulter, M. A.; and Knapp, R. W. Advanced System Development/Feasibility Techniques. New York: Wiley, 1982.

Denning, P.; Comer, D.; Gries, D.; Mulder, M.; Tucker, A.; Turner, A. J.; and Young, P. "Computing as a Discipline: Final Report of the Task Force on the Core of Computer Science," Communications of the ACM (32:1), January 1989, 1, pp. 9-23. 
Dickson, G. W.; Senn, J. A.; and Chervany, N. L. "Research in Management Information Systems: The Minnesota Experiments," Management Science (23:9), May 1977, pp. 913-923.

Forester, J. "Critical Ethnography: On Fieldwork in a Habermasian Way," in Critical Management Studies, M. Alvesson and H. Willmott (eds.). London: Sage Publications, 1992, pp. 46-65.

Galliers, R. D., and Land, F. L. "Choosing Appropriate Information Systems Research Methodologies." Communications of the ACM (30:11), 1987, pp. 900-902.

Greenbaum, J., and Kyng, M. (eds.). Design at Work: Cooperative Design of Computer Systems. Hillsdale, NJ: Lawrence Erlbaum Associates, 1991.

Hirschheim, R., and Klein, H. "Realizing Emancipatory Principles in Information Systems Development: The Case for ETHICS," MIS Quarterly (18:1), March 1994.

Hirschheim, R., and Klein H. K. "Four Paradigms of Information Systems Development," Communications of the ACM (32:10), 1989, pp. 1199-1216.

Hirschheim, R.; Klein, H. K.; and Lyytinen, K. Information Systems Development and Data Modeling: Conceptual and Philosophical Foundations. Cambridge, England: Cambridge University Press, 1995.

Ives, B.; Hamilton, J. S.; and Davis, G. B. “A Framework for Research in Computer-based MIS," Management Science, September 1980, pp. 910-934.

Kant, I. Groundwork of the Metaphysics of Morals, translated and analyzed by H. J. Patton. New York: Harper Torch Books, 1964.

Keen, P., and Scott-Morton M. S. Decision Support Systems: An Organizational Perspective. Reading, MA: Addison-Wesley, 1978.

Klein, H. K. "The Reconstruction of Design Ideals," paper presented at The Institute of Management Sciences Conference, Toronto, May 1981.

Klein, H. K., and Hirschheim, R. "The Rationality of Value Choices in Information Systems Development," Foundations of Information Systems [electronic journal:

http://www.cba.uh.edu/ parks/fis/fis.htm], http://www.cba.uh.edu/ parks/fis/kantpap.htm, 1998.

Klein, H. K., and Huynh, M. Q. "The Potential of the Language Action Perspective in Ethnographic Analysis," in New Information Technologies in Organizational Processes: Field Studies and Theoretical Reflections on the Future of Work, O. Ngwenyama, L. Introna, M. Myers, and J. I. DeGross (eds.). Norwell, MA: Kluwer, 1999.

Klein, H. K., and Lyytinen, K. "The Poverty of Scientism in Information Systems," in Research Methods in Information Systems, E. Mumford, R. Hirschheim, G. Fitzgerald and A. T.WoodHarper (eds.). Amsterdam: North-Holland, 1985.

Klein, H. K., and Lyytinen, K. "Data Modeling: Four Meta-Theoretical Assumptions," in Software Development and Reality Construction, C. Floyd, R. Budde and H. Zuellinghoven (eds.). Berlin: Springer, 1991, pp. 203-219.

Klein, H. K., and Myers, M. "A Set of Principles for Conducting and Evaluating Interpretive Field Studies in Information Systems," MIS Quarterly (23:1), March 1999, pp. 67-93. Quarterly, 1999.

Klein, H. K., and Truex, D. P. "Discourse Analysis: An Approach to the Analysis of Organizational Emergence," in The Semiotics of the Work Place, B. Holmqvist, B. P. Andersen, H. K. Klein, and R. Posner (eds.). Berlin: W. DeGruytner, 1996, pp. 227-268.

Kuhn, T. S. The Structure of Scientific Revolutions. Chicago: University of Chicago Press, 1970.

Kyng, M. "Designing for Cooperation: Cooperating in Design," Communications of the ACM (34:12), 1991, pp. 65-73.

Kyng, M., and Mathiassen, L. "System Development and Trade Union Activities," in Information Society for Richer for Poorer, N. Bjørn-Andersen (ed.). Amsterdam: North-Holland, 1982.

Land, F., and Hirschheim, R. "Participative Systems Design: Rationale, Tools and Techniques," Journal of Applied Systems Analysis (10), 1983. 
Lee, A. S.; Liebenau, J.; and DeGross, J. I. (eds.). Information Systems and Qualitative Research. London: Chapman \& Hall, 1997.

Mason, R. “A Dialectical Approach to Strategic Planning,” Management Science (15), April 1969, pp. B403-B414

Mathiassen, L. "Reflective Systems Development," accepted for publication in Scandinavian Journal of Information Systems, 1999/2000.

Mulder, M. "Power Equalization Through Participation?" Administrative Science Quarterly (16:1), 1971, pp. 31-38.

Mumford, E. Designing Participatively. Manchester, England: Manchester Business School, 1983.

Mumford, E. "Participation-From Aristotle to Today," on Beyond Productivity: Information Systems Development for Organizational Effectiveness, T. Bemelmans (ed.). Amsterdam: North Holland, 1984, pp 95-104.

Mumford, E.; Hirschheim, R.; Fitzgerald G.; and Wood-Harper, A. T. Research Methods in Information Systems. Amsterdam: North-Holland, 1985.

Ngwenyama, O. K., and Lee, A. S. "Communication Richness in Electronic Mail: Critical Social Theory and the Contextuality of Meaning," MIS Quarterly (21:2), June 1997, pp. 145-167.

Nissen, H. E.; Klein, H. K.; and Hirschheim, R. (eds.). Information Systems Research: Contemporary Approaches and Emergent Traditions. Amsterdam: North Holland, 1991.

Popper, K: Conjectures and Refutations. London: Routledge \& Kegan Paul, 1963.

Sanders,D. H. (ed.). Computers and Management. New York: McGraw Hill, 1970.

Schultze, U. "A Confessional Account of an Ethnography About Knowledge Work," accepted for publication MIS Quarterly, 1999.

\section{About the Author}

Heinz K. Klein earned his Ph.D. at the University of Munich and was awarded an honorary doctorate by the University of Oulu, Finland, for his academic contributions to the IS faculty's research program. He is currently Associate Professor of Information Systems at the State University of New York, Binghamton. Well known for his contributions to the philosophy of IS Research, foundations of IS theory and methodologies of information systems development, he has written articles on rationality concepts in ISD, the emancipatory ideal in ISD, principles of interpretive field research, alternative approaches to information systems development and their intellectual underpinnings. His articles have been published in the best journals of the field such as Communications of the ACM, MIS Quarterly, Information Systems Research, Information Technology and People, Decision Sciences, and others. He has also coauthored or edited several research monographs and conference proceedings in IS. He serves on the editorial boards of the Information Systems Journal, Information, Technology and People and the Wiley Series in Information Systems. He can be reached at hkklein@binghamton.edu. 